Scientific Journal of October 6 University

ISSN (Print): 2314-8640

ISSN (Electronic): 2356-8119

Published by October 6 University (C) All Rights Reserved

Available online at: http:// sjou.journals.ekb.eg
Citation: Hussein, (2017). Potential mechanisms for the antioxidant effects of Jasonia montana. Sci. J. of Oct. 6 Univ. 4(1), 1-8.

Copyright: (c) 2017 Hussein MA. This is an open-access article distributed under the terms of the Creative Commons Attribution License, which permits unrestricted use, distribution, and reproduction in any medium, provided the original author and source are credited.

Original Article

\title{
Potential mechanisms for the antioxidant effects of Jasonia montana
}

\author{
Mohammed A. Hussein \\ Department of Biochemistry, Faculty of Applied Medical Sciences, October 6 University, Egypt
}

Received: 10-05-2017/ Revised: 20-06-2017 / Accepted: 10-07-2017

\begin{abstract}
The use of medicinal plants as a dietary supplement is increasing in parallel with the research on it's therapeutically roles on human health. A literature survey indicated that polyphenols from Jasonia montana represent a promising antioxidant activity. Quercetin is the most common Jasonia montana polyphenols. Also, Jasonia montana quercetin derivatives act as antioxidants in vitro by scavenging reactive oxygen and nitrogen species and chelating redox-active transition metal ions. This review will discuss the mechanism of antioxidant and chelating activity of quercetin in an attempt to understand its mechanism of action, which may pave the way for possible therapeutic applications.
\end{abstract}

Key Words: Jasonia montana, antioxidants, chelating activity, quercetin and polyphenols

\section{Introduction}

In recent years, polyphenols have been reported to possess various pharmacological actions, including anti-obesity (Murase et al., 2002 and Ohta et al., 2005), antidiabetic (Ruzaidi et al., 2005 and Klein et al., 2007) and anti-cancer (Peng et al., 2006). Many plant extracts and plant products have been shown to have significant antiobesity and antidiabetic activities (Nagao et al., 2005 and Tomonori et al., 2007) which may be an important property of medicinal plants associated with the treatment of several ill fated diseases including obesity, diabetes and atherosclerosis. Plant-derived polyphenols minimize obesity induced diabetes (Knekt et al., 2002). Among these herbal resources, the plant Jasonia montana occurs in the Mediterranean and adjacent areas, (Merxmuller et al., 1977) including the Sinai Peninsula (Tackholm, 1974). The herb has a strong aromatic odor and is used in traditional medicine for diarrhea, stomachache, and chest diseases (Tackholm, 1974). Jasonia montana is one of the most common medicinal plants. The Jasonia montana owes its therapeutical activity to different groups of effective substances, which make up the complex effect of the drug. A literature survey indicated that some mono- and sesquiterpenes, (Tackholm, 1969; Eid et al., 1984; Ahmed et al., 1988 and Ahmed,
1991) flavonoids, (Ahmed et al., 1988) Essential oils are of greatest importance among all effective substances (Hammerschmidt et al., 1993). Polyphenols exist in many plants and are especially abundant in Jasonia Montana (Tawfeq et al., 2005), whose dried leaves are used as antioxidant. Jasonia montana and polyphenol-enriched plant extracts have no known toxicity. Thus polyphenols from Jasonia montana and possibly other plant sources represent a promising potential species (Hussein , 2008). These polyphenols are more potent antioxidants than vitamins $\mathrm{C}$ and $\mathrm{E}$ (Zhao et al., 1989). Polyphenol rich extracts from Jasonia montana inhibit lipid peroxidation in experimental animals (Hussein, 2008 and Hussein and AbdelGawad 2010). Not surprisingly, plants such as Jasonia montana contain high levels of polyphenols, (Zhao et al., 1989) which are excellent scavengers of reactive and represent a promising antiobesity effect. The different extracts of the plant were also tested for hypoglycemic, antidiabetic and anticholestatic activities (Hussein, 2008 and Hussein and Abdel-Gawad 2010). Recently, Hussein and Farghaly, (2010) studied the protective activity of Jasonia ethanolic extract against liver and kidney damage induced by ironoverloaded in adult rats and suggest that the aerial parts of $J$. montana extract may effectively

*Corresponding Author Address: Prof. Mohammed Abdalla Hussein: Department of Biochemistry, Faculty of Applied Medical Sciences, October 6 University, Egypt. E-mail: Prof.husseinma@o6u.edu.eg 
normalize the impaired antioxidant status in ironoverloaded rats model experiment. In vivo tests have been conducted with Jasonia montana to determine, for example, its, hypoglycemic (Hussein, 2008), antioxidant, anticholestatic (Hussein and Abdel-Gawad 2010) and antihaemostatic (Hussein and Farghaly, 2010) activities.

\section{a- Free radicals}

The term "free radicals" designates a family of compounds characterized by great reactivity due to the impaired electron in the outer orbital. To this group belong reactive oxygen species (ROS), such as superoxide anion, hydroxyl radical and hydrogen peroxide, as well as reactive nitrogen species (RNS) which include nitric oxide and peroxynitrite. Although structurally different, free radicals share similar mechanisms to harm body's cells and tissues through damage on proteins, DNA and lipids (Pauwels et al., 2007). The alterations of membrane functions occurring as a consequence of phospholipid modifications represent a relevant, radical species-dependent injury, either when considering the organism as a whole, or a specific integrated function, such as the immune response (Valko et al., 2007). The potential therapeutic applications of antioxidants in free radical-related diseases led to the hypothesis of their use to slow down or reverse, for example, symptoms associated with neurodegenerative disorders, such as Alzheimer's disease (AD) and Parkinson's disease (PD). Such effect could occur through a block of proinflammatory cytokines action and the resulting oxidative damage (Mancuso et al., 2007; Whitton, 2007; Ramassamy, 2006; Pham and Plakogiannis, 2005 and Drisko, 2002). However, several clinical studies demonstrated that not only malnutrition, but also the excess of certain nutrients (e.g. iron, alphatocopherol, beta-carotene, and ascorbic acid) may set into motion oxidation phenomena and, therefore, cell injury (Fang et al., 2002).

\section{b- Oxidative Stress}

The body is normally under a dynamic equilibrium between free radical generation and quenching. The physiological defense systems to counteract free radicals encompass endogenous enzyme systems, such as catalase, glutathione reductase and superoxide dismutase, as well as glutathione, urate and coenzyme $\mathrm{Q}$, or exogenous factors ( $\beta$ carotene, vitamin $\mathrm{C}$, vitamin $\mathrm{E}$ and selenium) (Mancuso et al., 2007). All these molecules have an antioxidant effect due to their ability to transform ROS into stable and harmless compounds or by scavenging both ROS and RNS with a redox based mechanism (Mancuso et al., 2007). Very recently, a main role in the fight against oxidative stress has been assumed by enzymes such as heme oxygenase (HO) and biliverdin reductase (BVR). Heme oxygenase is a microsomal enzyme which metabolizes heme into ferrous iron, carbon monoxide and biliverdin (BV); the latter is then reduced by BVR into bilirubin (BR), a molecule endowed with strong antioxidant and antinitrosative activities (Mancuso et al., 2006; Mancuso et al., 2006; Mancuso et al., 2003 and Grune and Berger, 2007). Interestingly, all these protective factors act in a concerted way, enhancing the antioxidant defense system of the cell. When the balance between ROS/RNS and antioxidants turns in favor of the former, oxidative/nitrosative stress occurs. Although oxidative stress is associated with most diseases, routine assay methods are not nowadays available in the clinical practice. A strategy widely used to determine oxidative stress is measurement of malony ldialdehyde, F2-isoprostanes, or 8- hydroxydesoxyguanosine. Actually, these molecules are regarded as the most reliable markers available (Gouni-Berthold and Sachinidis, 2004). A classic example of an oxidation product apparently leading to disease is oxidized cholesterol in low-density lipoprotein (LDL), which displays a higher atherogenic potential than native LDL, and mainly involved in the pathogenesis of atherosclerosis and coronary heart disease (CHD) (Bedogni et al., 2003).

At the cellular level, a large body of data clearly demonstrated that ROS, when produced in low amounts and in a controlled manner, are physiological components of the signalling generated by cytokines, growth factors and neurotrophic peptides Finkel, 2003; Colavitti et al., 2002; Pani et al., 2000; Pani et al., 2000; SchulzeOsthoff et al., 1993 and Jabs, 1999), although they may also activate apoptotic cell death (Hawkins et al., 2007). Extracellularly generated ROS can diffuse through anion channels into the cytoplasm; the resulting variation in the cell redox state leads to modulation of an array of transcription factors (eg. NFkB, AP-1), protein kinases (e.g. AKT, JNK, p38), and receptor activated MAP kinases involved in apoptosis (Bubici et al., 2006). Moreover, the proapoptotic molecules Fas and Fas ligand (FasL) undergo positive transcriptional regulation after exposure to oxidants (Weber et al., 2002). Interestingly, Krammer and Colleagues demonstrated that in vitro administration of vitamin E suppresses FasL mRNA expression and protects $\mathrm{T}$ cells of HIV-1 infected individuals from Fas mediated apoptosis (Haendeler et al., 1996). Moreover, it was demonstrated that administration of combinations of vitamin $\mathrm{E}$ and $\mathrm{C}$ to cultures of human umbilical vein endothelial cells (HUVEC) treated with lipopolysaccharide could prevent apoptosis by upregulation of $\mathrm{Bcl}-2$ (Fathy et al., 2009).

\section{c- Phytochemical studies:}

High content of flavonoids and phenolic compounds was found in Jasonia montana such as polyphenols , (Tackholm, 1969; Eid et al., 1984; 
Ahmed et al., 1988 and Ahmed, 1991); 3,6,7,3`,4`pentamethoxy quercetin (artemitin), 3,6,7,3 -tetramethoxy quercetin (chrysosplenetin), 3,6,3 ,4 tetramethoxy quercetin, 3,6,7- trimethoxy kaem-pferol, 3,6,3 -trimethoxy quercetin (jaceidin), 3,6,4 trimethoxy quercetin (centaureidin), 3, 3, 4 trimethoxy quercetin, 3,6-dimethoxy quercetin, 3,3'-dimethoxy quercetin, 7,4-dimethoxy quercetin, quercetin, quercetin-3-O- $\alpha-\mathrm{D}-4 \mathrm{C} 1$ - luco-pyranoside, 3,5dicaffeoyl-quinic acid, caffeic acid, quercetin-3-OL- 1C4- rhamnopyranoside (Quercitrin) and quercetin-3- O- $\alpha$ - D-4C1 glucuronopyranoside (Bouktaib et al., 2002) which may be responsible for free radical activity.There are eighteen phenolic quercetin derivatives were isolated from the chloroform, ethyl acetate and $\mathrm{n}$ butanol fractions of Jasonia montana (Bouktaib et al., 2002).

Most studies assessing the antioxidant properties of quercetin utilize the aglycone form; however, analysis of plasma after quercetin consumption indicates that quercetin metabolites, like glucuronide (quercetin-3-O- $\beta$-D-glucuronide), are the primary compounds circulating in the blood (Mohle, 1985). The metabolites are also what are primarily found in plants (Hollman, 1997). The aglycone is used in studies because there are few quercetin metabolites commercially available. The chemical structure of the metabolites, however, is possible (Figure 1).

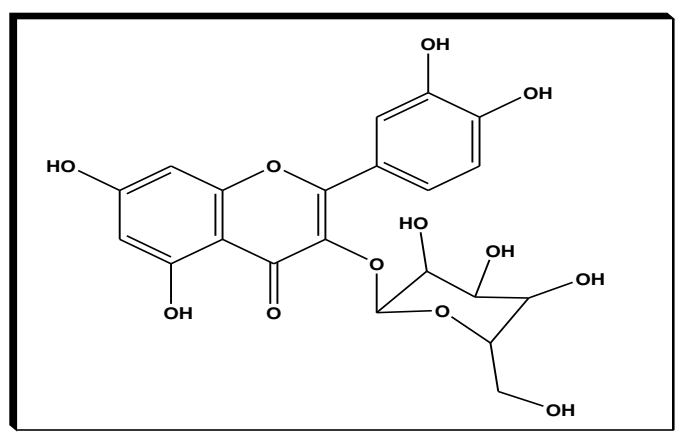

Figure 1. Quercetin-3-O-ß-glucoside (Sakanashi, 2008).

\section{d- The antioxidant properties of quercetin}

Quercetin is considered to be a strong antioxidant due to its ability to scavenge free radicals and bind transition metal ions. These properties of quercetin allow it to inhibit lipid peroxidation (Kahl and Hildebrandt, 1986 and Graf, 2008). Lipid peroxidation is the process by which unsaturated fatty acids are converted to free radicals via the abstraction of hydrogen.

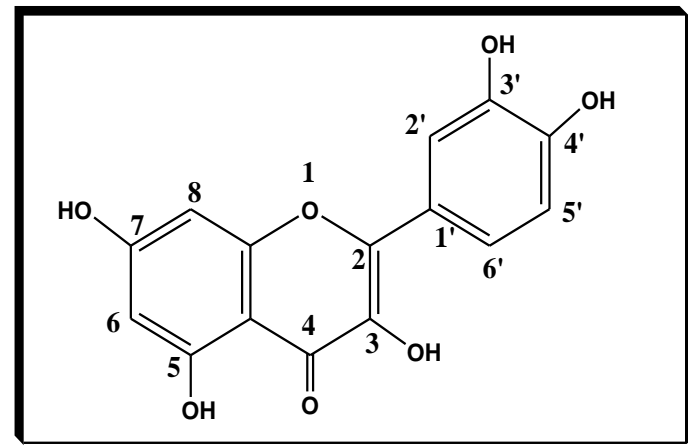

Figure 2. Quercetin

The subsequent free radicals are oxidized by molecular oxygen to create lipid peroxy radicals. This process is propagated by the resulting lipid peroxy radicals extracting hydrogen from other unsaturated fatty acid molecules to create more free radicals. It is catalyzed, in part, by the presence of trace amounts of transition metal ions. Lipid peroxidation can create deleterious effects throughout the body, such as cardiovascular and neurodegenerative diseases; however, it can be terminated by antioxidants, like quercetin, which interfere by reacting with the radicals formed (Chopra, 2000).

The oxidation of low-density lipoproteins (LDL) can result in the formation of atherosclerotic plaques, leading to cardiovascular disease (Graf, 2008). However, several studies have illustrated quercetin's ability to inhibit LDL oxidation. Graf and co-workers found a $21 \%$ reduction in cardiovascular disease mortality when the intake of quercetin was greater than $4 \mathrm{mg} / \mathrm{dl}$ (Balazse and Leon, 1994). Chopra, (2000), gave one group of males $30 \mathrm{mg} / \mathrm{d}$ of quercetin and another group $1 \mathrm{~g}$ of red wine powdered extract for two weeks, prior to which there had been a placebo period for all participants so that each could be their own control. The red wine extract was in the form of a powder and contained several flavonoids, among which quercetin constituted $3.5 \mathrm{mg}$ per gram of powder. Every participant was required to keep a journal of their intake of specific foods, including: fruits, vegetables, chocolates, fruit juices, milk, and alcohol. Vitamins $\mathrm{C}$ and $\mathrm{E}$ plasma concentrations were also measured along with flavonoids. They reported that the red wine extract and quercetin inhibited LDL and there was no effect on plasma concentrations of vitamin $\mathrm{C}$ and $\mathrm{E}$. However, plasma concentrations of LDL remained constant. Chopra and co-workers suggested that LDLcholesterol is only lowered by quercetin in hyperlipidemic patients; otherwise, quercetin inhibits LDL oxidation (Ansari et al., 2008).

The vulnerability of brain lipid membranes to lipid peroxidation is thought to lead to neurodegenerative disease, such as Alzheimer's and Parkinson's disease (Ansari et al., 2008). Balazs and Leon, (1994); found that oxidative 
stress occurring in the brain membrane lipids is associated with the extracellular accumulation of amyloid beta-peptide, which precedes neural losses in Alzheimer's patients. Yet, formation of amyloid plaques can be prevented by taking antioxidants (Harman, 1976 and Boots et al., 2008). In this situation, quercetin does not only stop the propagation of lipid peroxidation, but also increases glutathione (GSH) levels (Harman, 1976). GSH is part of the neuron's defense against oxidative damage. When the superoxide radical is formed, the radical can be converted to the hydrogen peroxide radical by superoxide dismutase; however, GSH can convert hydrogen peroxide to oxygen and water, preventing the formation of free radicals (Ansari et al., 2008).

Quercetin can also reduce inflammation by scavenging free radicals. Free radicals can activate transcription factors that generate pro-inflammatory cytokines, which are often found elevated in patients that suffer from chronic inflammatory diseases (Alexander, 1998). Chronic prostatitis is not well understood, but it is thought that the disease inflammates the genital tract. Alexander, (1998), examined semen samples taken from normal men and men with chronic prostatitis, measuring the levels of the cytokines tumor necrosis factor-alpha and interleukin- 1 beta. The results showed that men with the disease had higher levels of both pro-inflammatory cytokines in seminal plasma. In another study, Shoskes and coworkers administered men with chronic prostatitis $500 \mathrm{mg}$ of quercetin twice a day for one month. As a result, $67 \%$ of the men had a $25 \%$ improvement in symptoms.

Oxidative stress can cause cell death by means of prolonged elevations of intracellular $\mathrm{Ca}^{2+}$ concentrations (Graf, 2008). Elevated levels of $\mathrm{Ca}^{2+}$ concentrations lead to an increase in energy expenditure and subsequent initiation of cytoskeletal degradation, which can lead to strokes and acute neuronal losses (Begum and Terao, 2002). However, quercetin can protect cells suffering oxidative stress and thus prevent $\mathrm{Ca}^{2+}$ dependent cell death (Graf, 2008). In a 15 year study following 550 middle-aged men, those with a flavonol intake greater than $30 \mathrm{mg} / \mathrm{d}$ had a $60 \%$ reduction in their risk for strokes (Graf, 2008).

Quercetin can also protect against the more obvious environmental causes of free radicals, such as smoking. Cigarette tar is a source of free radicals, which has been found to damage erythrocyte membranes. Begum and Terao, (2002), found that the quercetin aglycone and its conjugate metabolites (quercetin-3-O-B-glucuronide and quercetin-3-O- $\quad \beta$-glucoside) could protect erythrocytes from the membranous damage that is caused by smoking. The control used in the study was flavone, which has the basic structure of quercetin but no hydroxyl groups, and it had no effect on the erythrocytes. This indicated that the hydroxyl groups are important to the antioxidant properties of quercetin.

e- Structural Criteria for the Antioxidant Action of quercetin.

Intensity of the antioxidant activity of a quercetin strongly depends on its chemical structure. There is a great deal of discussion and contradiction regarding the structure antioxidant activity relationships of flavonoids (van Acker et al., 1998 and Silva et al., 2002).

However, it is well-accepted that the antioxidant activity of flavonoids is markedly influenced by the number and position of hydroxyl groups on the $\mathrm{B}$ and $\mathrm{A}$ rings, and by the extent of conjugation between the B and C rings (Sichel et al., 1991; Chen et al., 1996; Rice-Evans et al., 1996 and van Acker et al., 1999). On the basis of many previous and recent findings (Bors et al., 1990; BenaventeGarcia et al., 1997; Miller et al., 1996; Maxwell et al., 1997; Saija et al., 1995; Bors et al., 2001; Bors and Michel, 2002 and Heijnen et al., 2004), it seems that favourable general structural requirements for effective radical scavenging and/or the antioxidative potential of quercetin follow the famous three Bors' criteria (2002):

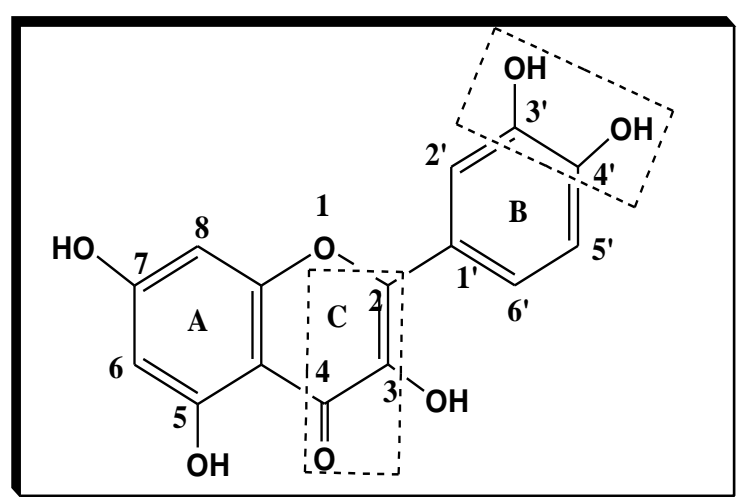

Fig. (3). Structural features of quercetin with high antioxidant activity.

a) The o-dihydroxy (3',4'-diOH, i.e., catechol) structure in the B ring, which confers high stability to the quercetin phenoxyl radical via hydrogen bonding or by expanded electron delocalization.

b) The C2-C3 double bond (in conjugation with the 4- oxo group), which determines the coplanarity of the heteroring and participates in radical stabilization via electron delocalization over all three ring systems.

c) The presence of both 3-OH and 5-OH groups for the maximal radical scavenging capacity and the strongest radical absorption. Moreover, an additional criterion could be added.

d) In the absence of $o$-dihydroxy structure in the B ring, hydroxyl substituents in a catechol structure on the A ring are able to compensate and become a larger determinant of flavonoid antiradical activity (Arora et al., 1998; Foti et al., 1996;Lemanska etal., 2001; Cai et al., 2006; Chung et al., 1998; 
2004 Butkovi et al., and Sesso, 1999). According to van Acker (Silva et al., 2002), the basic quercetin structure does not seem to be essential for good antioxidant activity. It becomes important only when the catechol moiety is not present.

\section{f- Mechanisms of the Antioxidant Action of quercetin}

Mechanisms of the antioxidant action of quercetin can include direct scavenging of reactive free radicals, chelating of trace metal ions involved in free radical formation, inhibition of enzymes involved in free radical production, and regeneration of membrane-bound antioxidants such as $\alpha$ tocopherol (Sroka et al., 2005). The antioxidant action of flavonoids can arise from direct scavenging of reactive oxygen species. It is generally considered that the primary mechanism of the radical scavenging activity of flavonoids is hydrogen atom donation. These antioxidants may also act by single-electron transfer. Structural requirements for the H-donating antioxidant activity include ortho-dihydroxy substitution in the B ring, C2-C3 double bond, and $\mathrm{C}-4$ carbonyl group in the $\mathrm{C}$ ring (Rice-Evans, 2002). In the hydrogen atom transfer mechanism, hydroxy groups donate hydrogen to a radical, stabilizing it and giving rise to a relatively stable flavonoid phenoxyl radical (Fig. 4a,b). The quercetin phenoxyl radical may react with a second radical (RO'), acquiring a stable quinone structure. The electron donation mechanism may be valid for the monohydroxyflavones, where hydrogen atom donation by other hydroxyl moieties is not an option. For 3-OH and/or 5- OH hydroxyflavones, the strong hydrogen bond of their $\mathrm{OH}$ moiety with the oxygen atom of the C-4 carbonyl group may prevent not only their efficient deprotonation, but also their radical scavenging action by means of hydrogen atom donation. The proposed mechanism of the antioxidant action of $\mathrm{C} 3-\mathrm{OH}$ or $\mathrm{C} 5-\mathrm{OH}$ hydroxyflavones is shown in (Fig. 4a, b).

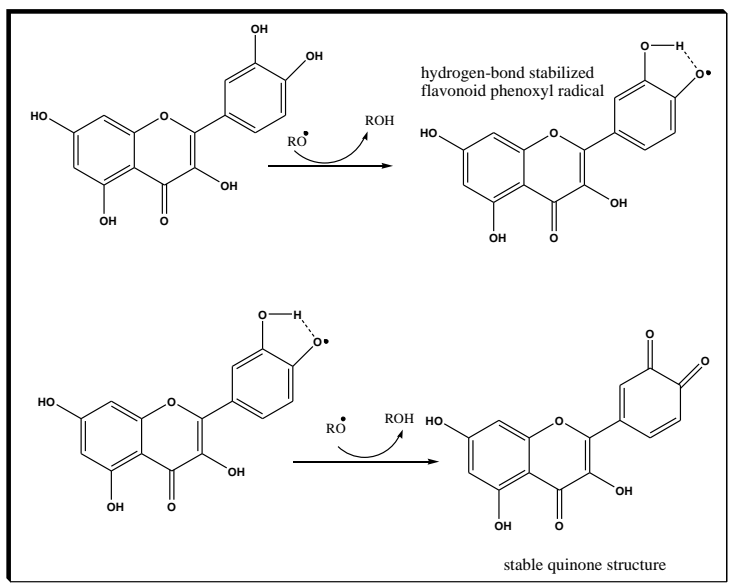

Fig. (4a). Mechanism of antioxidant action of 3',4'-diOH quercetin.

Structure A is the parent neutral molecule of 3hydroxyflavone, $\mathrm{B}$ is the initial radical cation (resulting from electron abstraction from the neutral molecule), and $\mathrm{C}$ is its more stable tautomeric form. The tautomeric form $\mathrm{C}$ of the radical cation results from the initial radical cation $\mathrm{B}$ and the proton transfer from $\mathrm{C} 3-\mathrm{OH}$ to the $\mathrm{C}-4$ carbonyl group.

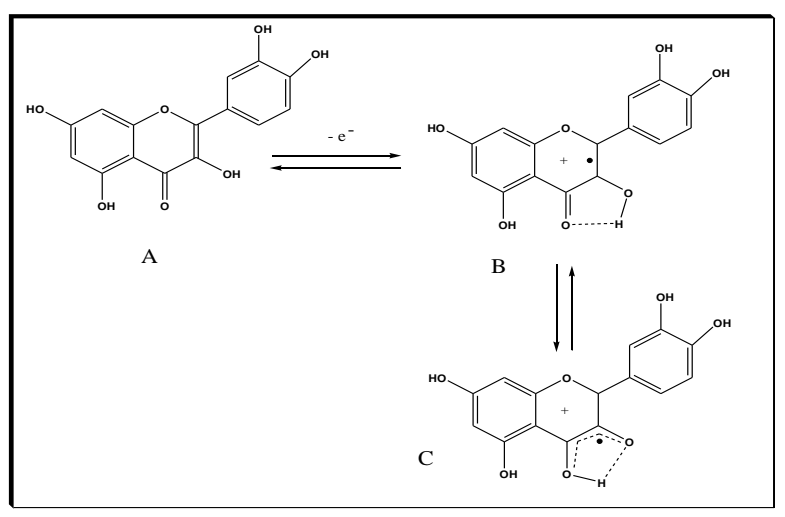

Fig. (4b). Mechanism of antioxidant action of C3$\mathrm{OH}$ or $\mathrm{C} 5-\mathrm{OH}$ quercetin.

A number of flavonoids efficiently chelate trace metal ions, such as $\mathrm{Fe}^{2+}$ and $\mathrm{Cu}^{+}$that play an important role in oxygen metabolism and free radical formation (Sakanashi, 2008).. Free iron (II) and copper (I) help the formation of reactive oxygen species, as exemplified by the reduction of hydrogen peroxide (Fenton reaction) with generation of the highly aggressive hydroxyl radical:

$$
\mathrm{H}_{2} \mathrm{O}_{2}+\mathrm{Fe}^{2+}\left(\mathrm{Cu}^{+}\right) \rightarrow \mathrm{HO}^{\bullet}+\mathrm{OH}^{-}+\mathrm{Fe}^{3+}\left(\mathrm{Cu}^{2+}\right)
$$

The proposed binding site for trace metal ions to quercetin is the 3',4'-diOH moiety in the $\mathrm{B}$ ring. In addition, $\mathrm{C}-3$ and $\mathrm{C}-5 \mathrm{OH}$ groups and the 4carbonyl group also contribute to metal ion chelation (Fig. 5). Besides scavenging free radicals directly and chelating transition metal ions by masking their prooxidant actions, flavonoids also behave as antioxidants through inhibition of prooxidant enzymes. This mechanism seems to be responsible for their in vivo effects (Guzik et al., 2006). Non-antioxidant mechanisms of flavonoid action, such as modulation of signalling pathways and gene expression, could also contribute to protective properties of quercetin (Williams et al., 2004).

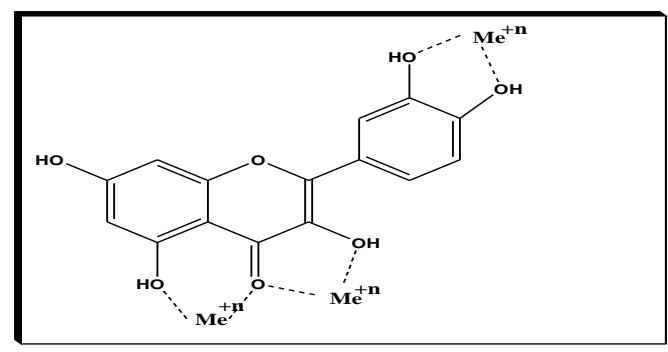


Fig. (5). Binding sites for trace elements (Sakanashi, 2008).

\section{Conclusion}

There is increasing evidence to suggest that antioxidant action is not the fundamental process that leads to any health benefits of Jasonia montana polyphenols. It seems likely that any activity occurs at a more fundamental level related to enzyme interaction and gene expression. Quercetin exhibits a range of activities. Antioxidant activity is unique in that rather than describing a physiological function it describes a chemical reactivity based on the oxidizability of these compounds. The question is whether this reactivity is expressed in physiological conditions and, if so, what are the oxidation products and, perhaps more importantly, what is the physiological significance of such reactivity? Similar questions can be asked of the products of quercetin metabolism in the liver and by intestinal microflora. On the other hand, the reactivity of polyphenols as reflected in their antioxidant potential means that certain quercetin derivatives can bind with proteins impacting their behavior. Although polyphenol concentrations in plasma are below levels expected to show bioactivity, non-covalent interaction with protein provides a means of delivery to target organs/tissues where their localized concentrations may exert the observed effects.

\section{References}

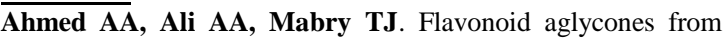
Jasonia montana, Phytochemistry. 1989;28:665-7.

Ahmed AA. Two geraniol derivatives from Jasonia montana, Pharmazie. 1991;46:362-63.

Ahmed, AA, Jakupovic, Eid JF, Ali AA. 11-Hydrojasionone; A new sesquiterpene type from Jasonia montana, Phytochemistry. 1988; 27:3875-77.

Alexander, RB. Elevated levels of pro-inflammatory cytokines in the semen of patients with chronic prostatitis/chronic pelvic pain syndrome. Urology, 1998, 52: 744-749.

Ansari, M.Protective effect of quercetin in primary neurons against $A \beta$ (1-42): relevance to Alzheimer's disease. Journal of Nutritional Biochemistry. 2008, 4:572-578.

Arora A, Nair MG, Strasburg GM. The antioxidant activity of flavonoids in cell-free systems has been studied extensively. Free Radic. Biol. Med., 1998, 24: 1355-1363.

Balazs, $\mathbf{L}$ and M. Leon. Evidence of an oxidative challenge in the Alzheimer's brain. Neurochemical Research. 1994, 19: 1131-1137.

Bedogni B, Pani G, Colavitti R, Riccio A, Borrello S, Murphy M, Smith R, Eboli ML, Galeotti T: Redox regulation of cAMP-responsive element-binding protein and induction of manganous superoxide superoxide dismutase in nerve growth factor-dependent cell survival. J Biol Chem 2003, 278:1651016519 .

Begum, AN and J. Terao. Protective effect of quercetin against cigarette tar extract-induced impairment of erythrocyte deformability. Journal of Nutritional Biochemistry . 2002, 13: 265-272.

Benavente-Garcia O, Castillo J, Marin FR, Ortuno A, Del Rio JA. Citrus Polymethoxylated Flavones Can Confer Resistance against Phytophthora citrophthora, Penicillium digitatum, and Geotrichum Species. J. Agric. Food Chem., 1997, 45: 4505-4515.

Boots, AW. In vitro and ex vivo anti-inflammatory activity of quercetin in healthy volunteers. Nutrition. 2008, 24: 703-710.

Bors W, Heller W, Michel C, Saran M. In Methods in Enzymology; Packer, L.; Glazer, A.N. Eds.; Academic Press: San Diego, CA, 1990; Vol. 186, pp. 343-355.

Bors W, Michel C, Stettmaier K. Structure-activity relationships governing antioxidant capacities of plant polyphenols. Methods Enzymol., 2001, 335: 166-180.

Bors W, Michel C. Chemistry of the antioxidant effect of polyphenols. Ann. N.Y. Acad. Sci., 2002, 957: 57-69.

Bouktaib, M. Regio- and stereoselective synthesis of the major metabolite of quercetin, quercetin-3-O-b-D-glucuronide. Tetrahedron Letters 2002, 43: 6263-6266.

Bubici C, Papa S, Dean K, Franzoso G: Mutual cross-talk between reactive oxygen species and nuclear factor-kappa B: molecular basis and biological significance. Oncogene 2006, 25(51):6731-6748

Butkovi V, Klasinc L, Bors W. On-line HPLC method for screening of antioxidants against superoxide anion radical from complex mixtures. J. Agric. Food Chem., 2004, 52: 2816-2820.

Cai YZ, Sun M, Xing J, Luo Q, Corke H. Structure-radical scavenging activity relationships of phenolic compounds from traditional Chinese medicinal plants.Life Sci., 2006, 78: 2872 2882.

Chen ZY, Chan PT, Ho KY, Fung KP. Wang. Antioxidant activity of tea theaflavins and methylated catechins in canola oil. J. Chem. Phys. Lipids 1996, 79: 157-163.

Chopra, M. Nonalcoholic red wine extract and quercetin inhibit LDL oxidation without affecting plasma antioxidant vitamin and carotenoid concentrations. Clinical Chemistry. 2000, 46: 11621170 .

Chung KT, Wong TY, Huang YW, Lin Y (1998). Tannins and human health: a review. Crit. Rev. Food Sci. Nutr. 1998, 38: 421-464.

Colavitti R, Pani G, Bedogni B, Anzevino R, Borrello S, Waltenberger J, Galeotti T: Reactive oxygen species as downstream mediators of angiogenic signaling by vascular endothelial growth factor receptor-2/KDR. J Biol Chem 2002, 277:3101-3108 
Drisko JA: The use of antioxidants in transmissible spongiform encephalopaties: a case report. J Am Coll Nutr 2002, 21(1):2225.

Eid F, El-Dahmy S, Gupta PK. Constituents from Jasonia montana and Allagopuppus dicotoma Pharmazie. 1987;42:42324.

Fang Y, Yang S, Wu G: Free radicals, antioxidants and nutrition. Nutrition 2002, 18(10):872.

Fathy MS, Mohamed YM, Hossam MA, Samir MO.Cytotoxic activity of flavonoids of Jasonia montana Vahl. (Botsch). (Astraceae) growing in Egypt. Australian Journal of Basic and Applied Sciences. 2009;3:148-52.

Finkel T: Oxidant signals and oxidative stress. Curr Opin Cell Biol 2003, 15(2):247-254

Foti M, Piattelli M, Baratta M T, Ruberto G. Flavonoids, coumarins, and cinnamic acids as anti-oxidants in a micellar system. Structure-activity relationship. J. Agric. Food Chem. 1996, 44: 497-501.

Gouni-Berthold I, Sachinidis A: Possible non-classic intracellular and molecular mechanisms of LDL cholesterol action contributing to the development and progression of atherosclerosis. Curr Vasc Pharmacol 2004, 2(4):363-370.

Graf, B. Flavonols, flavones, flavanones, and human health: epidemiological evidence. Journal of Medicinal Food. 2008, 8: 281-290.

Grune T, Berger MM: Markers of oxidative stress in ICU clinical settings: present and future. Curr Opin Clin Nutr Metab Care 2007.

Guzik TJ, Harrison DG. Vascular NADPH oxidases as drug targets for novel antioxidant strategies. Drug Discov. Today, 2006, 11: 524-533.

Haendeler JH, Zeiher AM, Dimmeler S: Vitamin C and E prevent lipopolysaccharide-induced apoptosis in human endothelial cells by modulation of Bcl-2 and Bax. Eur $\mathrm{J}$ Pharmacol 1996, 317:407-411.

Hammerschmidt FJ, Clark AM, Soliman FM, El- Kashoury ESA, Abd El-awy MM, El-Fishawy AM. Chemical composition and antimicrobial activity of essential oils of Jasonia candicans and Jasonia montana, Planta Medica.1993;59:68-70.

Harman, D. Free-radical theory of aging-inhibition of amyloidosis in mice by antioxidants-possible mechanism. American Geriatrics Society. 1976, 24: 203-210.

Hawkins BJ, Madesh M, Kirkpatrick CJ, Fisher AB: Superoxide flux in endothelial cells via the chloride channel-3 mediates intracellular signaling. Mol Biol Cell 2007, 18(6):2002-2012.

Heijnen CGM, Haenen GRMM, van Acker FAA, van der Vijgh WJF, Bast A. Peroxynitrite scavenging of flavonoids: structure activity relationship. Environmental Toxicology and Pharmacology. 2004, 10: 199-206.

Hollman, PCH and M.B. Katan. Absorption, metabolism and health effects of dietary flavonoids in man. Biomed. \& Pharmacother.1997, 51: 305-310.

Hussein MA, Abdel-Gawad SM. Protective effect of Jasonia montana against ethinylestradiol induced cholestasis in rats. Saudi Pharmaceutical Journal. 2010;18:35-45.

Hussein MA, Farghaly HS. Protective Effects of Jasonia montana Against Lipid Peroxidation in Liver and Kidney of Iron-overloaded Rats. Australian Journal of Basic and Applied Sciences. 2010;4:2004-12.

Hussein MA. Antidiabetic and antioxidant activity of Jasonia Montana extract in streptozotocin-induced diabetic rats. Saudi Pharmaceutical Journal. 2008;16:214-21.

Jabs T: Reactive oxygen intermediates as mediators of programmed cell death in plants and animals. Biochem Pharmacol 1999, 57:231-245.

Kahl, R and A.G. Hildebrandt. Methodology for studying antioxidant activity and mechanisms of action of antioxidants. Food and Chemical Toxicology. 1986, 24: 1007-1014.

Klein G, Kim J, Himmeldirk K, Cao Y, Chen X. Antidiabetes and anti-obesity activity of Lagestroemia speciosa. Evid Based Complement Alternat Med. 2007;4:401-7.

Knekt P, Kumpulainen J, Jarvinen R, Rissanen H, Heliovaara M, Reunanen A, Hakulinen T, Aromaa A. Flavonoid intake and risk of chronic diseases. Am. J. Clin. Nutr. 2002;76:560-8.
Lemanska K, Szymusiak H, Tyrakowska B, Zielinski R, Soffers AEMF, Rietjens IMCM. The Influence of $\mathrm{pH}$ on Antioxidant Properties and the Mechanism of Antioxidant Action of Hydroxyflavones. Free Radic. Biol. Med., 2001, 31: 869-881.

Mancuso C, Bates TE, Butterfield DA, Calafato S, Cornelius C, De Lorenzo A, Dinkova Kostova AT, Calabrese V: Natural antioxidants in Alzheimer's disease. Expert Opin Investig Drugs 2007, 16(12):1921-1931.

Mancuso C, Bonsignore A, Capone C, Di Stasio E, Pani G: Albuminbound bilirubin interacts with nitric oxide by a redox mechanism. Antioxid Redox Signal 2006, 8(3-4):487-494.

Mancuso C, Bonsignore A, Di Stasio E, Mordente A, Motterlini R: Bilirubin and S-nitrosothiols interaction: evidence for a possible role of bilirubin as a scavenger of nitric oxide. Biochem Pharmacol 2003, 66(12):2355-2363.

Mancuso C, Pani G, Calabrese V: Bilirubin: an endogenous scavenger of nitric oxide and reactive nitrogen species. Redox Rep 2006, 11(5):207-213.

Mancuso C, Scapagnini G, Currò D, Giuffrida Stella AM, De Marco C, Butterfield DA, Calabrese V: Mitochondrial dysfunction, free radical generation and cellular stress response in neurodegenerative disorders. Front Biosci 2007, 12:11071123.

Maxwell D R J, Lip G Y H : Free radicals and antioxidants to cardiovascular disease. Br. J. Clin. Pharmacol. 1997, 44: 307317

Merxmuller H, Liens P, Roesseler H. In: J.B. Heywood, J.B. Harborne and B.L. Turner (Eds.), The Biology and Chemistry of Compositae, 1977; p. 590. Academic Press, New York.

Miller N J, Castelluccio C, Tijburg L, Rice-Evans CA. The antioxidant properties of theaflavins and their gallate esters radical scavengers or metal chealtors? FEBS Lett. 1996, 392:4044.

Mohle, B. UV-induced biosynthesis of quercetin 3-0-B-Dglucuronide in dill cell cultures. Phytochemistry 1985, 3: 465467

Murase T, Nagasawa A, Suzuki J, Hase T, Tokimitsu I. Beneficial effects of tea catechins on diet-induced obesity: stimulation of lipid catabolism in the liver. Int J Obes Relat Metab Disor. 2002;26: 1459-64.

Nagao T, Komine Y, Soga S. Ingestion of a tea rich in catechins leads to a reduction in body fat and malondialdehydemodified LDL in men. Am J Clin Nutr. 2005;81:122-9.

Ohta Y, Sami M, Kanda T, Saito K, Osada K, Kata H. Gene expression analysis of the anti-obesity effect by apple polyphenols in rats fed a high fat diet or a normal diet. $J$ Oleo Sci 2006;55: 305-14.

Pani G, Colavitti R, Bedogni B, Anzevino R, Borrello S, Galeotti T: A redox signaling mechanism for density-dependent inhibition of cell growth. J Biol Chem 2000, 275:38891-38899. Pani G, Colavitti R, Borrello S, Galeotti T: Endogenous oxygen radicals modulate protein tyrosine phosphorylation and JNK-1 activation in lectin-stimulated thymocytes. Biochem $\mathbf{J}$ 2000, 347:173-181.

Pauwels EK, Erba PA, Kostkiewicz M: Antioxidants: A tale of two stories. Drug News Perspect 2007, 20(9):579-585.

Peng G, Dixon DA, Muga SJ, Smith TJ, Wargovich MJ. Green tea polyphenols -epigallocatechin-3-gallate inhibits cyclooxygenase-2 expression in colon carcinogenesis. Mol Carcinog. 2006;45:309-19.

Pham DQ, Plakogiannis R: Vitamin E supplementation in Alzheimer's disease, Parkinson's disease, tardive dyskinesia, and cataract: Part 2. Ann Pharmacother 2005, 39(12):2065-2072.

Ramassamy C: Emerging role of polyphenolic compounds in the treatment of neurodegenerative diseases: a review of their intracellular targets. Eur J Pharmacol 2006, 545(1):51-64.

Rice-Evans CA, Miller NJ, Paganga G. Structure-antioxidant activity relationships of flavonoids and phenolic acids. Free Radic. Biol. Med., 1996, 20: 933-966.

Rice-Evans, C. Why do we Expect Flavonoids to Function as Antioxidants in vivo? 2002

http://www.medicine.uiowa.edu/frrb/SRFRS/www/SFRS2002/p df/-SFRS2002 RiceFlavonoids.pdf 
Ruzaidi A, Amin I, Nawalyah AG, Hamid M, Faizul HA. The effect of Malaysian cocoa extract on glucose levels and lipid profiles in diabetic rats. J Ethnopharmacol. 2005;98:55-60. Saija A, Scalese M, Lanza M, Marzullo D, Bonina F, Castelli F : Flavonoids as antioxidant agents: Importance of their interaction with biomembranes. Free Radical Biol. Med. 1995, 19: 481-486.

Sakanashi, Y. Possible use of quercetin, an antioxidant, for protection of cells suffering from overload of intracellular $\mathrm{Ca}^{2+}$ : a model experiment. Life Sciences 2008, 83: 164-169.

Schulze-Osthoff K, Beyaert R, Vandevoorde V, Haegeman G, Fiers W: Depletion of the mitochondrial electron transport abrogates the cytotoxic and gene-inductive effects of TNF. EMBO J 1993, 12:3095-3104

Sesso H D. Coffee and tea intake and the risk of myocardial infarction. Am J Epidemiol. 1999, 149: 162-7.

Sichel G, Corsaro C, Scalia M, Di Bilio AJ, Bonomo RP. In vitro scavenger activity of some flavonoids and melanins against $\left.\mathrm{O}_{2}{ }^{-(}\right)$. Free Radic. Biol. Med., 1991, 11: 1-7.

Silva MM, Santos MR, Caroco G, Rocha R, Justino G, Mira L. Structure-antioxidant activity relationships of flavonoids: a re-examination. Free Radic. Res., 2002, 36: 1219-1228.

Soobrattee MA, Neergheen VS, Luximon-Ramma A,

Arouma OI, Bahorun T. Phenolics as potential antioxidant therapeutic agents: mechanism of actions. Mutat. Res., 2005, 579: 200-213.

Sroka ZZ. Antioxidative and antiradical proper- ties of plant phenolics. Naturforsch., 2005, 60c: 833-844.

Tackholm V. Alfred Kaiser's Sinai-Herbarium, 1969; p. 562. Cairo University Herbium, Cairo. 21. Ahmed AA, Jakupovic. Sesqui and monoterpenes from Jasonia montana. J. Phytochemistry. 1990;29:3656-61.

Tackholm V. Students Flora of Egypt, 1974; p. 562. Cairo University, Beirut.
Tawfeq A, Adnan J, AL-Rehailyb, Joanna R, Polsc, John R, Porter, Jaber S, Mossab, Bahar Ahmed. Three new diterpenes and the biological activity of different extracts of Jasonia Montana. Natural Product Research. 2005;19:253-65.

Tomonori N, Tadashi H, Ichiro T. A Green Tea Extract High in Catechins Reduces Body Fat and Cardiovascular Risks in Humans. Obesity. 2007;6:1473-83.

Valko M, Leibfritz D, Moncol J, Cronin MT, Mazur M, Telser J: Free radicals and antioxidants in normal physiological functions and human disease. Int J Biochem Cell Biol 2007, 39(1):44-84.

van Acker SABE, Bast A, van der Vijgh, WJF. In: Flavonoids in Health and Disease; Rice-Evans, C.A.; Packer, L., Eds.; Marcel Dekker: New York, 1998, pp. 221-251.

van Acker SABE,van den Berg, DJ, Tromp MNJL, Griffioen DH, van Bennekom WP, van der Vijgh WJF, Bast A. A partial least squares regression study with antioxidant flavonoid compounds. Free Radic. Biol. Med., 1996, 20: 331 342 .

Weber ML, Weigand MA, Giaisi M, Suss D, Treiber MK, Baumann S, Ritsou E, Breitkretz R, Krammer PH: Vitamin E inhibits CD95 ligand expression and protects $\mathrm{T}$ cell from activation-induced cell death. J Clin Invest 2002, 110:681-690.

Whitton PS: Inflammation as a causative factor in the aetiology of Parkinson's disease. Br J Pharmacol 2007, 150(8):963-976. Williams RJ, Spencer JPE, Rice-Evans C. Free Radical Biology \& Medicine. Free Radic. Biol. Med., 2004, 36: 838-849.

Zhao B, Li X, He R, Cheng S, Xin W. Scavenging effect of extracts of green tea and natural antioxidants on active oxygen radicals. Cell Biophys. 1989;14:175-85. 